\title{
Predictors of successful patent ductus arteriosus closure with acetaminophen in preterm infants
}

\author{
Ruben Vaidya $\mathbb{B}^{1} \cdot$ Alexander Knee ${ }^{2,3} \cdot$ Yvonne Paris $^{4} \cdot$ Rachana Singh $^{1}$
}

Received: 15 April 2020 / Revised: 28 July 2020 / Accepted: 25 August 2020 / Published online: 2 September 2020

(c) The Author(s), under exclusive licence to Springer Nature America, Inc. 2020

\begin{abstract}
Objective Evaluate predictors of successful PDA closure following acetaminophen treatment.

Study design Retrospective cohort study of $\leq 30$ weeks GA infants born from 1 January 2013-30 September 2019, and treated with single course acetaminophen by symptomatic PDA treatment strategy. Multiple maternal and neonatal variables were identified as potential predictors. Univariate analysis and multivariable regression models were applied to evaluate the strongest predictors.

Results Sixty-six patients were included, 28 (42.4\%) had successful PDA closure following acetaminophen. Success was associated with $\mathrm{GA}>26$ weeks $(65 \%$ vs. $33 \%, \mathrm{AUC}=0.64)$, birthweight $>750 \mathrm{~g}(53 \%$ vs. $32 \%, \mathrm{AUC}=0.61)$, PDA size $\leq 0.2 \mathrm{~cm}(63 \%$ vs. $32 \%$, AUC $=0.64)$, and no prior indomethacin use $(56 \%$ vs. $33 \%$, AUC $=0.61)$. Multivariable model identified GA $>26$ weeks ( $R R=1.92$, CI $1.20-3.09)$ and PDA size $\leq 0.2 \mathrm{~cm}$ (RR: 1.82, CI $1.11-2.98)$ as the strongest predictors.
\end{abstract}

Conclusion Acetaminophen may be more successful in targeted PDA closure in $>26$ weeks GA infants with PDA size $\leq 0.2 \mathrm{~cm}$.

\section{Introduction}

Management of hemodynamically significant patent ductus arteriosus (hs-PDA) continues to be controversial with no consensus on the definition, need/timing for treatment and/ or treatment choices. Medical management of patent ductus arteriosus (PDA), with nonselective cyclo-oxygenase inhibitors like indomethacin and ibuprofen, is still considered the primary choice as compared to surgical management

Ruben Vaidya

ruben.vaidyaMD@baystatehealth.org

1 Division of Newborn Medicine, Department of Pediatrics, University of Massachusetts Medical School - Baystate, Springfield, MA 01199, USA

2 Epidemiology and Biostatistics Research Core, Office of Research, Baystate Medical Center, University of Massachusetts Medical School - Baystate, Springfield, MA 01199, USA

3 Department of Medicine, University of Massachusetts Medical School - Baystate, Springfield, MA 01199, USA

4 Division of Pediatric Cardiology, Department of Pediatrics, University of Massachusetts Medical School - Baystate, Springfield, MA 01199, USA with its associated risks [1]. However, several adverse effects have been reported with these medications including gastrointestinal bleeding and perforation, decreased platelet aggregation, hyperbilirubinemia, renal failure [2-4], thrombocytopenia, and hyponatremia [5].

Acetaminophen is an analgesic and antipyretic derivative of acetanilide that is increasingly being used as an alternative for medical management of the PDA. Multiple recent randomized controlled trials (RCTs) [4, 6-13] and a metaanalysis [1] have reported acetaminophen to be as effective as indomethacin and ibuprofen for PDA closure, with potentially fewer adverse effects.

The probability of successful PDA closure with acetaminophen may vary, as most RCTs have reported 70-80\% successful PDA closure rates [6-11, 14], while we recently reported a 40\% successful PDA closure using a symptomatic PDA closure strategy [15]. Multiple factors including gestational age (GA), birth weight (BW), small for gestational age (SGA) status, day of life (DOL) at treatment, duration of treatment, exposure to antenatal corticosteroids (ANCS), severity of respiratory distress, Caucasian race, and intrauterine inflammation have been reported to be associated with successful PDA closure with indomethacin [16-19]. However, to date, an evaluation to determine if 
these factors may be associated with successful PDA closure following acetaminophen has not been conducted. Our study objective was to identify the clinical predictors associated with successful PDA closure following acetaminophen treatment in preterm infants born $<30$ weeks gestation.

\section{Methods}

This is a single center, retrospective cohort study performed at a Level III Neonatal Intensive Care Unit located at Baystate Children's Hospital, regional perinatal referral center for western Massachusetts with the capability of surgical management of hs-PDA. All infants $\leq 30$ weeks and 0 days GA, born between January 2013 and September 2019, with PDA and treated with acetaminophen as first line treatment, using symptomatic PDA treatment strategy, were included in the study. Twins were considered separate subjects for study purposes if both were treated with acetaminophen for PDA. Small for gestational age (SGA) infants, defined as those with birthweight $<10$ th percentile for age based on Fenton growth charts for premature infants were also included [20]. Infants with any significant congenital cardiac, pulmonary, neurologic anomalies, or any significant genetic conditions were excluded from the study. Infants who received PDA treatment with acetaminophen and died later were also included in the study. The study was approved by Baystate Medical Center Institutional Review Board.

Our overall PDA management strategy included the treatment of only symptomatic hs-PDA in patients with need for continued increased respiratory support. Symptomatic PDA treatment strategy is currently the most widely used clinical approach [21], but is also the most difficult to classify due to variation in attributing clinical significance of PDA to varying degrees of ventilator dependency and/or cardiovascular compromise [22]. PDA was considered hemodynamically significant if moderate-sized or largesized based on pediatric cardiologist's evaluation and/or PDA size $\geq 1.5 \mathrm{~mm}$, with additional echocardiographic findings (left atrial enlargement evidenced by left atrial: aortic root ratio (LA:Ao) of $>1.4$, absent or reversal of flow in the descending aorta, or left ventricular dilatation) and/or clinical findings (metabolic acidosis with base excess $<-7$, mean blood pressure less than weeks in gestation or requiring vasopressor support, bounding pulses/hyperactive precordium) and with continued need for significant respiratory support. Prior to 2015 only infants who had a contraindication to indomethacin were treated with acetaminophen, but since 2015 acetaminophen has been used as the standard first line medication for medical management of PDA. Acetaminophen dosage was similar to other reported studies as $15 \mathrm{mg} / \mathrm{kg} / \mathrm{dose}$, orally or intravenously, every 6 hour for 3 days [23]. We evaluated for successful PDA closure following a single 3 day course of acetaminophen with no prior treatment of the PDA. Successful PDA closure was defined as no PDA or small PDA, based on post-treatment echocardiogram officially assessed by the pediatric cardiologists, using a definition of PDA diameter $<1.5 \mathrm{~mm}(\mathrm{GA} \leq 26$ weeks) or $<2.0 \mathrm{~mm}(\mathrm{GA} \leq 30$ weeks) as "small" or "hemodynamically nonsignificant" [24]. Pretreatment echocardiogram was obtained for all patients prior to initiation of PDA treatment. Post-treatment echocardiogram was obtained for all infants within 24 hours of treatment completion, except when the treatment was completed over the weekend, and the repeat echocardiogram was obtained on the first working weekday. All infants were classified either as successful PDA closure group (small or no PDA) or nonsuccessful PDA closure group (no change or increase in PDA size). Although minor practice variations did exist among the neonatologists, our overall PDA management strategy was treating hs-PDA only in an infant requiring significant respiratory support. Our clinical practice also includes routine administration of indomethacin for intraventricular hemorrhage (IVH) prophylaxis for all infants born $<750 \mathrm{~g}$ (dosage: $0.1 \mathrm{mg} / \mathrm{kg} /$ dose, every 24 hour for 3 days) without screening echocardiograms. For this study prophylactic indomethacin for IVH prevention was not considered as treatment of PDA.

The clinical factors identified as predictors of interest were evaluated as binary categorizations of: GA ( $<26$ weeks vs. $>26$ weeks), BW ( $<750 \mathrm{~g}$ vs. $>750 \mathrm{~g})$, treatment DOL (Early: $\leq 7$ DOL vs. Late: $>7$ DOL), corrected GA at the time of treatment ( $\leq 28$ weeks vs. $>28$ weeks), route of administration (oral vs. intravenous), SGA status (vs. appropriate for GA infants), use of ANCS versus none, prior prophylactic indomethacin administration for prevention of IVH vs. none, need for invasive mechanical ventilation (vs. noninvasive respiratory support), fraction of inspired oxygen $\left(\mathrm{FiO}_{2}\right)$ need at treatment $(\leq 0.3$ vs. $>0.3)$, maternal chorioamnionitis vs. none, total fluid volume (TFV) prescribed during the treatment time period (low TFV: $<130 \mathrm{ml} / \mathrm{kg} /$ day vs. high $\mathrm{TFV}>130 \mathrm{ml} / \mathrm{kg} /$ day). Additionally, we studied the ordinally scaled PDA size (moderate to large and large PDA vs. moderate size PDA), PDA size ( $>0.2 \mathrm{~cm}$ vs. $\leq 0.2 \mathrm{~cm})$ and LA/Ao ratio ( $>1.5$ vs. $\leq 1.5$ ), which were assigned by the pediatric cardiologist reading the echocardiograms. For all patients with unsuccessful PDA closure following initial acetaminophen treatment, further data regarding follow-up PDA treatments and/ or surgical intervention, pre/post PDA treatment sizes and follow-up success rates were also collected.

For statistical analysis, we initially evaluated the differences in neonatal characteristics by the presence or absence of successful PDA closure. Categorical variables are 
presented as frequencies and percentages (e.g., predicted probabilities of successful closure), whereas continuous variables are presented as means and standard deviations. We then performed a univariable analysis (Fisher exact test for categorical variables and Wilcoxon rank-sum for continuous variables), however as our sample size was small, power was limited, and therefore statistical testing was meant to be exploratory in nature. Of particular interest were categorical predictors, which we assessed by calculating the relative risk (RR) and 95\% confidence intervals (CI) using log-binomial models. To assess overall discrimination, we used the area under the curve (AUC) where an AUC of 0.5 indicates no discrimination (like flipping a coin). To simultaneously evaluate which predictors had possibly the strongest associations, we explored a multivariable log-binomial model. Due to the small number of outcome events (e.g., successful PDA closure), we followed a common rule of thumb in which we selected approximately one predictor for every ten events. To select predictors, we chose those with an AUC $>0.60[25,26]$ and reduced our model to the fewest relevant predictors. Statistical analysis was conducted using Stata version 16.0, StataCorp, LP, College Station, TX.

\section{Results}

A total of 66 patients met inclusion criteria with mean GA of $25.5+2.1$ weeks and mean BW 783.1 + 264.6 g. Mean age at initiation of PDA treatment was $11.0+8.2$ days (Median: 8 days, IQR: 5-13 days) (Table 1). 30 (45.5\%) of the patients were treated within seven DOL, while 36 $(54.5 \%)$ were treated after seven DOL. Table 1 describes the baseline demographic information and clinical characteristics of the infants included in the study. There were 46 infants (69.7\%) born at $\leq 26$ weeks GA, $34(51.5 \%)$ had BW $<750 \mathrm{~g}, 44(66.7 \%)$ were treated at corrected GA $<$ 28 weeks and $50(75.8 \%)$ were treated with intravenous acetaminophen (Table 2).

Successful PDA closure was achieved in 28 (42.4\%) infants following acetaminophen as first line of treatment for PDA.

Infants with successful PDA closure were more likely to be higher GA $(26.3+2.4$ weeks vs. $24.9+1.6$ weeks, $p=0.009)$, higher BW $(861.3+303.1 \mathrm{~g}$ vs. $725.5+219 \mathrm{~g}$, $p=0.038)$ and higher corrected GA $(27.9+2.6$ weeks vs. $26.5+2.1$ weeks, $p=0.016$ ) (Table 1 ). On univariate analysis, successful PDA closure was associated with higher birth GA $(65 \%$ for $>26$ weeks vs. $33 \%$ for $\leq 26$ weeks, $\mathrm{AUC}=0.64)$, higher $\mathrm{BW}(53 \%$ for $>750 \mathrm{~g}$ vs. $32 \%$ for $\leq 750 \mathrm{~g}, \mathrm{AUC}=0.61$ ) and higher corrected GA (59\% for $>28$ weeks vs. $34 \%$ for $\leq 28$ weeks, $\mathrm{AUC}=0.61$ ) (Table 2). No exposure to indomethacin for IVH prophylaxis in the first 3 days of life was associated with increased successful PDA closure rates after acetaminophen $(56 \%$ vs. $33 \%, \mathrm{AUC}=0.61)($ Table 2$)$. In our sample, there was no association between DOL at treatment, acetaminophen route of administration, SGA status, ANCS exposure, invasive mechanical ventilation at time of treatment, $\mathrm{FiO}_{2}$ need at the time of treatment, maternal chorioamnionitis, and TFV administered with successful PDA closure (Table 2).

Smaller PDA size was also associated with higher successful PDA closure rates following acetaminophen $(60 \%$ for $\leq 0.2 \mathrm{~cm}$ vs. $32 \%$ for $>0.2 \mathrm{~cm}, \mathrm{AUC}=0.64$ ), while LA/ Ao ratio did not correlate with successful PDA closure (Table 3).

In our multivariable model, we entered GA, BW, PDA size, and prior indomethacin exposure. Although corrected GA was also identified as a possible predictor, this was collinear with birth GA which had a larger AUC, and hence corrected GA was left out of the model. Since degree of respiratory support (invasive vs. noninvasive; and $\mathrm{FiO}_{2}$ needs) did not show any association in the univariate model, they were not included in the multivariate model. Our final model suggested that both GA and PDA size were the strongest predictors of successful PDA closure. Infants with GA $>26$ weeks at birth were nearly twice as likely to have a successful PDA closure than infants with GA $\leq 26$ weeks $(\mathrm{RR}=1.92,95 \% \mathrm{CI}=1.20-3.09)$; and infants with a PDA size $\leq 0.2 \mathrm{~cm}$ were nearly twice as likely to have a successful PDA closure than infants with PDA size $>0.2 \mathrm{~cm}$ ( $\mathrm{RR}=$ 1.82; 95\% CI 1.11-2.98) (Table 4).

Additionally, we also looked at the treatment course of all infants with failed PDA closure following acetaminophen $(n=38)$. There were 15 infants that were further treated with a second course of acetaminophen and only three $(20.0 \%)$ had successful PDA closure after a failed first course of acetaminophen. A total of 18 infants were further treated with indomethacin, either as second or third course of PDA treatment after failed acetaminophen treatment, and only four infants $(22.2 \%)$ had successful PDA closure and nine eventually required surgical PDA ligation. A total of 15 infants (39.5\%) underwent surgical ligation due to failure of the initial acetaminophen course. There were no differences in any of the other short-term clinical outcomes (length of stay, severe retinopathy of prematurity, severe IVH, surgical necrotizing enterocolitis, bronchopulmonary dysplasia (BPD), death, and death or BPD) in the two groups.

\section{Discussion}

Acetaminophen is increasingly being used for initial medical management of PDA as demonstrated by multiple case 
Table 1 Demographic characteristics and echocardiogram findings of infants included in the study.

\begin{tabular}{|c|c|c|c|c|}
\hline & \multirow{2}{*}{$\begin{array}{l}\text { Total } \\
(n=66) n(\%)\end{array}$} & \multicolumn{2}{|c|}{ Successful PDA closure } & \multirow[t]{2}{*}{$p$-value ${ }^{\mathrm{a}}$} \\
\hline & & No $(n=38) n(\%)$ & Yes $(n=28) n(\%)$ & \\
\hline $\begin{array}{l}\text { Gestational age (weeks), Mean } \\
\text { (SD) }\end{array}$ & $25.5(2.1)$ & $24.9(1.6)$ & $26.3(2.4)$ & $0.009 *$ \\
\hline Birth weight (g), Mean (SD) & $783.1(264.6)$ & $725.5(219.0)$ & $861.3(303.1)$ & $0.038^{*}$ \\
\hline Male, $n(\%)$ & $34(51.5)$ & $17(44.7)$ & $17(60.7)$ & 0.223 \\
\hline Vaginal delivery, $n(\%)$ & $21(31.8)$ & $12(31.6)$ & $9(32.1)$ & 1.0 \\
\hline \multicolumn{5}{|l|}{ Race, $n(\%)$} \\
\hline White & $6(9.1)$ & $2(5.3)$ & $4(14.3)$ & 0.227 \\
\hline African-American & $51(77.3)$ & $31(81.6)$ & $20(71.4)$ & \\
\hline Other & $9(13.6)$ & $5(13.2)$ & $4(14.3)$ & \\
\hline Hispanic, $n(\%)$ & $26(39.4)$ & $14(36.8)$ & $12(42.9)$ & 0.799 \\
\hline 5 min APGAR, median (IQR) & $7.0(5.0,8.0)$ & $7.0(5.0,8.0)$ & $6.5(5.5,8.0)$ & 0.772 \\
\hline Antenatal steroids, $n(\%)$ & $53(80.3)$ & $32(84.2)$ & $21(75.0)$ & 0.369 \\
\hline Small for gestational age, $n(\%)$ & $14(21.2)$ & $8(21.1)$ & $6(21.4)$ & 1.0 \\
\hline Maternal chorioamnionitis, $n(\%)$ & $20(30.3)$ & $13(34.2)$ & $7(25.0)$ & 0.799 \\
\hline $\begin{array}{l}\text { Corrected gestational age at } \mathrm{Rx} \\
\text { (weeks), mean (SD) }\end{array}$ & $27.1(2.4)$ & $26.5(2.1)$ & $27.9(2.6)$ & $0.016^{*}$ \\
\hline \multicolumn{5}{|l|}{ Acetaminophen route, $n(\%)$} \\
\hline IV & $50(75.8)$ & $27(71.1)$ & $23(82.1)$ & 0.388 \\
\hline $\mathrm{PO}$ & $16(24.2)$ & $11(28.9)$ & $5(17.9)$ & \\
\hline $\begin{array}{l}\text { Invasive mechanical ventilation } \\
\text { at } \mathrm{Rx}, n(\%)\end{array}$ & $42(63.6)$ & $26(68.4)$ & $16(57.1)$ & 0.439 \\
\hline $\begin{array}{l}\mathrm{FiO}_{2} \text { at the time of treatment, } \\
\text { mean(SD) }\end{array}$ & $35.51(14.0)$ & $35.99(11.7)$ & $34.86(16.8)$ & 0.748 \\
\hline $\begin{array}{l}\mathrm{TFV}<130 \mathrm{ml} / \mathrm{kg} / \text { day at the time } \\
\text { of } \mathrm{Rx}, n(\%)\end{array}$ & $9(13.6)$ & $5(13.2)$ & $4(14.3)$ & 0.589 \\
\hline $\begin{array}{l}\text { Prior indomethacin for IVH } \\
\text { prophylaxis, } n(\%)\end{array}$ & $39(59.1)$ & $26(68.4)$ & $13(46.4)$ & 0.083 \\
\hline \multicolumn{5}{|l|}{ PDA size, $n(\%)$} \\
\hline Moderate & $38(57.6)$ & $19(50.0)$ & $19(67.9)$ & 0.361 \\
\hline Moderate-large & $5(7.6)$ & $3(7.9)$ & $2(7.1)$ & \\
\hline Large & $23(34.8)$ & $16(42.1)$ & $7(25.0)$ & \\
\hline PDA size $(\mathrm{cm})$, Mean $(\mathrm{SD})$ & $0.23(0.06)$ & $0.24(0.05)$ & $0.21(0.05)$ & 0.064 \\
\hline LA/Ao ratio, Mean (SD) & $1.54(0.26)$ & $1.51(0.22)$ & $1.58(0.32)$ & 0.335 \\
\hline
\end{tabular}

$P D A$ patent ductus arteriosus, $S D$ standard deviation, $T F V$ total fluid volume, $\mathrm{FiO}_{2}$ fraction of inspired oxygen, $R x$ treatment, IQR interquartile interval (25th -75 th percentiles).

${ }^{a}$ t-tests were conducted for continuous variables represented as mean (SD), whereas Wilcoxon rank sum was used for continuous variables represented as median (IQR). Fisher exact test was used for categorical variables. ${ }^{*} p$-value $<0.05$. series [23, 27, 28] and recent randomized controlled trials [4, 6-10, 12, 14]. In our study, with symptomatic PDA treatment strategy, we found that infants $>26$ weeks GA or with PDA size $\leq 0.2 \mathrm{~cm}$ were nearly twice as likely to have successful PDA closure after acetaminophen compared to infants $\leq 26$ weeks or with PDA size $>0.2 \mathrm{~cm}$. Both $>26$ weeks GA and PDA size $\leq 0.2 \mathrm{~cm}$ were independent predictors of successful PDA closure. These results are in line with published studies, which report lower GA to be an independent risk factor for failure of ductal closure with indomethacin $[16,17,29]$. Similarly, larger PDA is known to be more resistant to successful closure with indomethacin [30, 31].

We report a lower probability of successful PDA closure (42.4\%) following acetaminophen compared to the previous published RCTs, which range from 70 to $100 \%$ successful PDA closure [4, 6-12, 14]. This is likely related to differences in the patient population of the enrolled subject as well as our unit's clinical practice of symptomatic PDA treatment strategy used to treat hs-PDA, which were potentially causing pulmonary comorbidity of continued need for mechanical ventilation and inability to wean. Most 
Table 2 Clinical characteristics of successful vs. nonsuccessful PDA closure groups.

\begin{tabular}{|c|c|c|c|c|c|c|}
\hline & \multirow{2}{*}{$\begin{array}{l}\text { Total } \\
(n=66) n(\%)\end{array}$} & \multicolumn{2}{|c|}{ Successful PDA closure } & \multirow[t]{2}{*}{$p$-value } & \multirow[t]{2}{*}{$\mathrm{RR}(95 \% \mathrm{CI})$} & \multirow[t]{2}{*}{ AUC } \\
\hline & & No $(n=38) n(\%)$ & Yes $(n=28) n(\%)$ & & & \\
\hline \multicolumn{7}{|c|}{ Gestational age (weeks) } \\
\hline$\leq 26$ & $46(69.7)$ & $31(67.4)$ & $15(32.6)$ & $0.03^{\#}$ & Referent & 0.64 \\
\hline$>26$ & $20(30.3)$ & $7(35.0)$ & $13(65.0)$ & & $1.99(1.18,3.37)$ & \\
\hline \multicolumn{7}{|c|}{ Birth weight $(\mathrm{g})$} \\
\hline$\leq 750$ & $34(51.5)$ & $23(67.6)$ & $11(32.4)$ & 0.14 & Referent & $0.61^{*}$ \\
\hline$>750$ & $32(48.5)$ & $15(46.9)$ & $17(53.1)$ & & $1.64(0.91,2.95)$ & \\
\hline \multicolumn{7}{|c|}{ Day of life at $\mathrm{Rx}$ (days) } \\
\hline$\leq 7$ & $30(45.5)$ & $18(60.0)$ & $12(40.0)$ & 0.81 & Referent & 0.52 \\
\hline$>7$ & $36(54.5)$ & $20(55.6)$ & $16(44.4)$ & & $1.11(0.63,1.97)$ & \\
\hline \multicolumn{7}{|c|}{ Corrected gestational age at $\mathrm{Rx}$} \\
\hline$\leq 28$ & $44(66.7)$ & $29(65.9)$ & $15(34.1)$ & 0.07 & Referent & 0.61 \\
\hline$>28$ & $22(33.3)$ & $9(40.9)$ & $13(59.1)$ & & $1.73(1.01,2.97)$ & \\
\hline \multicolumn{7}{|c|}{ Acetaminophen route } \\
\hline $\mathrm{PO}$ & $16(24.2)$ & $11(68.8)$ & $5(31.3)$ & 0.39 & Referent & 0.56 \\
\hline IV & $50(75.8)$ & $27(54.0)$ & $23(46.0)$ & & $1.47(0.67,3.23)$ & \\
\hline \multicolumn{7}{|c|}{ Small for gestational age } \\
\hline No & $52(78.8)$ & $30(57.7)$ & $22(42.3)$ & 1.0 & Referent & 0.50 \\
\hline Yes & $14(21.2)$ & $8(57.1)$ & $6(42.9)$ & & $1.01(0.51,2.01)$ & \\
\hline \multicolumn{7}{|c|}{ Antenatal betamethasone } \\
\hline No & $13(19.7)$ & $6(46.2)$ & $7(53.8)$ & 0.37 & Referent & 0.55 \\
\hline Yes & $53(80.3)$ & $32(60.4)$ & $21(39.6)$ & & $0.74(0.40,1.34)$ & \\
\hline \multicolumn{7}{|c|}{ Prior indomethacin for IVH prophylaxis } \\
\hline No & $27(40.9)$ & $12(44.4)$ & $15(55.6)$ & 0.08 & Referent & 0.61 \\
\hline Yes & $39(59.1)$ & $26(66.7)$ & $13(33.3)$ & & $0.60(0.34,1.05)$ & \\
\hline \multicolumn{7}{|c|}{ Invasive mechanical ventilation at $R x$} \\
\hline No & $24(36.4)$ & $12(50.0)$ & $12(50.0)$ & 0.44 & Referent & 0.56 \\
\hline Yes & $42(63.6)$ & $26(61.9)$ & $16(38.1)$ & & $0.76(0.44,1.33)$ & \\
\hline \multicolumn{7}{|c|}{$\mathrm{FiO}_{2}$ at the time of treatment } \\
\hline$\leq 0.3$ & $26(39.4)$ & $14(53.8)$ & $12(46.2)$ & 0.80 & Referent & 0.53 \\
\hline$>0.3$ & $40(60.6)$ & $24(60.0)$ & $16(40.0)$ & & $0.87(0.49,1.52)$ & \\
\hline \multicolumn{7}{|c|}{ Maternal chorioamnionitis } \\
\hline No & $46(69.7)$ & $25(54.3)$ & $21(45.7)$ & 0.59 & Referent & 0.55 \\
\hline Yes & $20(30.3)$ & $13(65.0)$ & $7(35.0)$ & & $0.77(0.39,1.51)$ & \\
\hline \multicolumn{7}{|c|}{ Low $\mathrm{TFV}<130 \mathrm{ml} / \mathrm{kg} /$ day } \\
\hline No & $57(86.4)$ & $33(57.9)$ & $24(42.1)$ & 1.0 & Referent & 0.51 \\
\hline Yes & $9(13.6)$ & $5(55.6)$ & $4(44.4)$ & & $1.06(0.48,2.33)$ & \\
\hline
\end{tabular}

$P D A$ patent ductus arteriosus, $I V H$ intraventricular hemorrhage, $\mathrm{Rx}$ treatment, $\mathrm{FiO}_{2}$ fraction of inspired oxygen, $T F V$ total fluid volume. ${ }^{\#} p$-value $<0.05, *$ AUC $>0.6$ published RCTs to date are from the eastern hemisphere, enrolling larger GA infants with mean GA>30 weeks $[6,9,10,12,13]$, larger BW infants with BW 1000-1500 g $[7,11]$ and $>1500 \mathrm{~g}[6,9,10]$ infant with only one study enrolling infants $<28$ weeks GA [11]. Most preterm infant $\geq 28$ weeks of gestation spontaneously close the PDA by the end of the first postnatal week [16, 17, 32, 33], while $50-70 \%$ of infants $<28$ weeks of gestation may have a moderate-to-large PDA shunt persisting for weeks after birth [34, 35]. Meanwhile, our patients were considerably younger with a mean GA of $25.5+2.1$ weeks and mean BW of $783+264 \mathrm{~g}$, which could explain a lower PDA closure rate when compared to other published studies. Additionally, the PDA treatment strategy followed may be different in the RCTs compared to our practice. Most studies had used a prophylactic or early symptomatic PDA treatment strategy with most patients enrolled or treated within the first 3-5 DOL (Table 5). The one RCT which enrolled infants $<28$ weeks GA, likely also used an early PDA treatment strategy, as the mean DOL at treatment was $2.7+0.6$ days [11]. On the other hand, our clinical practice is expectant management with watchful waiting and symptomatic PDA treatment when necessary, which is a commonly used approach in North America [22, 36, 37]. Hence, the PDA treatment for our cohort of infants was delayed with mean DOL of treatment of $11+8.2$ days, and may also have contributed to the lower closure rate. Among all infants who failed PDA closure following acetaminophen, they also had a poor response to follow-up indomethacin treatment (total $n=18$, with 4 (22.2\%) successful PDA closures) further suggesting that the strategy of delayed treatment might have contributed to the lower overall success rate rather than the choice of medication itself. Since 15 of the 38 patients $(39.5 \%)$ who failed to have PDA closure following acetaminophen eventually required surgical ligation, this also suggests that these PDA 
Table 3 PDA characteristics of successful vs. nonsuccessful PDA closure groups.

\begin{tabular}{|c|c|c|c|c|c|c|}
\hline & \multirow{2}{*}{$\begin{array}{l}\text { Total }(n=66) \\
n(\%)\end{array}$} & \multicolumn{2}{|c|}{ Successful PDA closure } & \multirow[t]{2}{*}{$p$-value } & \multirow[t]{2}{*}{$\mathrm{RR}(95 \% \mathrm{CI})$} & \multirow[t]{2}{*}{ AUC } \\
\hline & & $\begin{array}{l}\text { No }(n=38) \\
n(\%)\end{array}$ & $\begin{array}{l}\text { Yes }(n=28) \\
n(\%)\end{array}$ & & & \\
\hline \multicolumn{7}{|l|}{ PDA size } \\
\hline Moderate/Moderate-large & $43(65.2)$ & $22(51.2)$ & $21(48.8)$ & 0.20 & Referent & 0.59 \\
\hline Large & $23(34.8)$ & $16(69.6)$ & $7(30.4)$ & & $\begin{array}{l}0.62 \\
(0.31,1.24)\end{array}$ & \\
\hline \multicolumn{7}{|l|}{ PDA size $(\mathrm{cm})$} \\
\hline$>0.2$ & $41(62.1)$ & $28(68.3)$ & $13(31.7)$ & $0.04^{\#}$ & Referent & $0.64^{*}$ \\
\hline$\leq 0.2$ & $25(37.9)$ & $10(40.0)$ & $15(60.0)$ & & $\begin{array}{l}1.89 \\
(1.09,3.28)\end{array}$ & \\
\hline \multicolumn{7}{|l|}{ LA/Ao ratio } \\
\hline$\leq 1.5$ & $41(62.1)$ & $25(61.0)$ & $16(39.0)$ & 0.61 & Referent & 0.54 \\
\hline$>1.5$ & $25(37.9)$ & $13(52.0)$ & $12(48.0)$ & & $\begin{array}{l}1.23 \\
(0.70,2.15)\end{array}$ & \\
\hline
\end{tabular}

PDA patent ductus arteriosus, LA/Ao Left atrium:aortic root. ${ }^{*} p$-value $<0.05$, *AUC $>0.6$.
Table 4 Predictors of successful PDA closure with acetaminophen.

\begin{tabular}{|c|c|c|}
\hline & $\begin{array}{l}\text { Probability of successful PDA } \\
\text { closure } n \%(95 \% \mathrm{CI})\end{array}$ & $\begin{array}{l}\text { Relative risk } \\
(95 \% \mathrm{CI})^{\mathrm{a}}\end{array}$ \\
\hline \multicolumn{3}{|c|}{ Gestational age (weeks) } \\
\hline$\leq 26$ & $33.0(20-46.0)$ & Referent \\
\hline$>26$ & $63.4(45.3-81.5)$ & $1.92(1.20-3.09)$ \\
\hline \multicolumn{3}{|c|}{ PDA size $(\mathrm{cm})$} \\
\hline$>0.2$ & $32.2(18.6-45.7)$ & Referent \\
\hline$\leq 0.2$ & $58.6(41.9-75.3)$ & $1.82(1.11-2.98)$ \\
\hline
\end{tabular}

PDA patent ductus arteriosus.

${ }^{\mathrm{a}}$ Based on multivariable log binomial regression model.

might have been larger and more resistant to pharmacological closure. Additionally, another recent randomized control trial reported only a $42.4 \%$ successful PDA closure rate with initial acetaminophen course $(71.4 \%$ cumulative closure rate with two courses) in infants with mean GA of 32.1 weeks and treated at mean DOL 9. This further suggests that delayed treatment of PDA may be associated with relatively lower successful PDA closure rate even in relatively larger preterm infants [13].

Our results are similar to the multicenter PDATOLERATE trial, which also reported a lower successful PDA closure rate with acetaminophen. The trial enrolled $<28$ weeks GA infants and randomized them at $8.1 \pm$ 2.1 days to either early drug treatment arm or conservative management with potential for rescue treatment arm after seven DOL. Twenty-six infants in the early drug treatment arm and 15 infants in the conservative arm were eventually treated with acetaminophen with 7/26 (27\%) and 6/15 (40\%) success rate, respectively in the two arms [38]. Interestingly, one other recent open label randomized control trial has reported a very low successful PDA closure rate $(5.9 \%)$ with a mean GA of $25.7+1.4$ weeks GA and BW $785+203 \mathrm{~g}$, with median PDA treatment days of 8 days. This study had a small sample size of 17 patients in the acetaminophen arm, and enrollment for this trial was stopped earlier by the data safety monitoring board due to poor efficacy [39]. The results of these studies which include smaller GA infants and using symptomatic PDA treatment strategy, combined with our results suggest that acetaminophen may have a lower successful PDA closure rated in infant born $<28$ weeks with symptomatic PDA treatment strategy in comparison to indomethacin. This is also supported by in vitro and in vivo preclinical studies, which found acetaminophen to be less effective than cyclooxygenase inhibitors in very immature animals $[27,40]$. Hence, in less mature infants (especially those $\leq 26$ weeks) its efficacy is significantly reduced in comparison to indomethacin [38, 41].

Prior studies have reported associations between exposure to maternal betamethasone to play a role in determining the success of drug-induced closure during the first days after birth [16, 42]. However, we did not find any association between maternal ANCS exposure on ductal closure, probably due to the rationale that these risk factors may no longer play a role in the rate of ductus constriction when PDA treatment is started after the first week. We also did not find any significant association between ductal closure and SGA status, maternal chorioamnionitis, TFV prescribed at the time of treatment, DOL at the time of treatment, infant respiratory status, oxygen needs, acetaminophen administration route or other clinical factors. This is likely due to our small sample size rendering low power to detect meaningful differences, or due to difference in treatment strategy as most of the prior studies have focused on an 


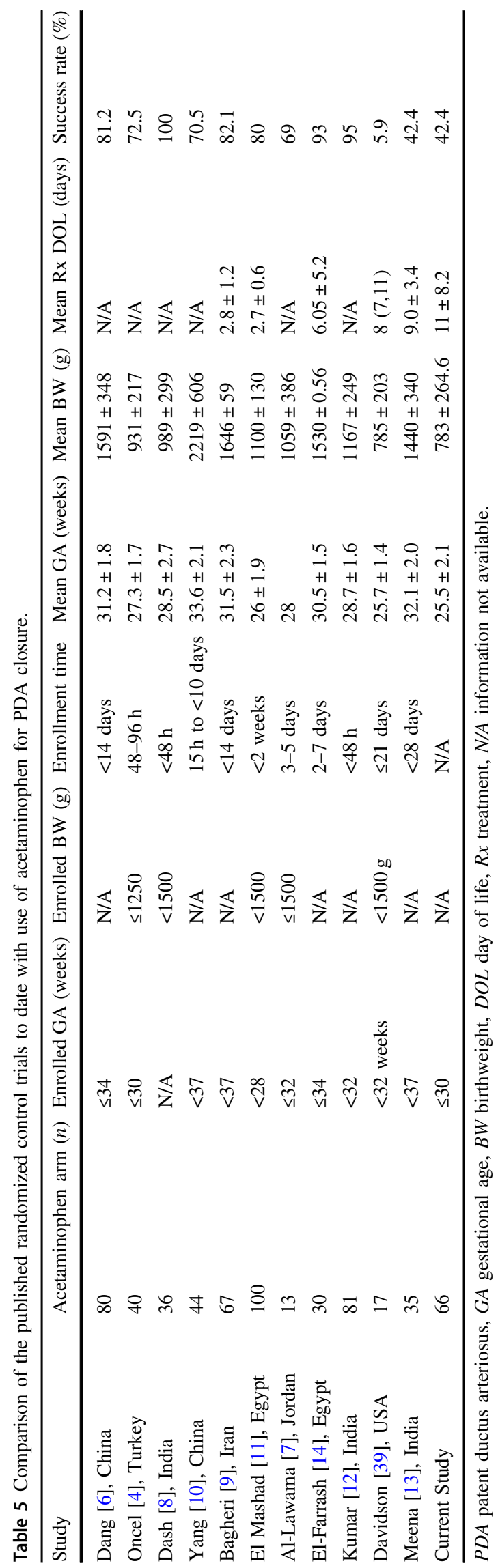

earlier PDA treatment strategy compared to our current practice. In addition, the cut off points of our variables may not be identifying clinically important thresholds with regards to successful PDA closure and a larger sample size may be able to address these issues. Our clinical practice also includes routine administration of indomethacin for IVH prophylaxis for all infant born $<750$ grams for the first three DOL. No study to date has evaluated the effectiveness of PDA closure with acetaminophen following prior indomethacin exposure directly, but it has been demonstrated from multiple studies that prophylactic indomethacin usage is associated with lower prevalence of PDA [43, 44]. As all our study subjects had a moderate or large PDA as part of the inclusion criteria, and on average were treated at $11.0+$ 8.2 days of life, we speculate that prophylactic indomethacin may not have affected PDA closure with acetaminophen. Interestingly, in our study population, exposure to indomethacin for IVH prophylaxis was associated with decreased successful PDA closure rates as compared to infants who had not received prophylactic indomethacin (33\% vs. $56 \%$, AUC $=0.61)$. We speculate that this association was likely secondary to the fact that only infants with lower BW and GA received prophylactic indomethacin, and hence they had lower successful PDA closure following acetaminophen, which is consistent with the rest of the results. After removing all patient who received prophylactic indomethacin $(n=39)$, in the remaining 27 infant, acetaminophen had $55.6 \%$ successful PDA closure rate, which is higher than overall $42 \%$ successful closure rate in the entire cohort, again likely due to selecting out a cohort with higher BW.

Although our study is limited by single center retrospective data collection and a small sample size; the data was exclusively extracted by neonatologist and cardiologist to maintain its accuracy. The utilization of an evidencebased clinical practice guideline regarding PDA diagnosis and management in a small group of closely working physicians is one of the strengths of our study. Although, we did not have any acute short term complications associated with acetaminophen usage, we do not have long term follow-up data available for these patients, which may be important as there have been some concerns regarding long outcome following acetaminophen exposure [45, 46]. There are at least 19 ongoing trials ongoing that would provide additional evidence regarding this topic [1].

In conclusion, in our study, we report an overall lower successful PDA closure rate following acetaminophen treatment when using symptomatic PDA closure strategy. Both GA $>26$ weeks and PDA size $\leq 0.2 \mathrm{~cm}$ were associated with higher probability of successful PDA closure following acetaminophen. Acetaminophen may be more useful in targeted PDA closure in infants $>26$ weeks GA and PDA size $\leq 0.2 \mathrm{~cm}$. Future studies with a larger sample size with symptomatic treatment strategy for medical management of 
PDA are needed to identify the most efficacious and safest agent with highest probability of successful closure.

Acknowledgements We thank Department of Pediatrics, University of Massachusetts Medical School- Baystate for ongoing research support.

Author contributions RV: Conceptualization, methodology, investigation, data curation, formal analysis, writing initial manuscript, reviewed final version of the manuscript. AK: Methodology, investigation, formal analysis, reviewed final version of the manuscript. YP: Conceptualization, methodology, investigation, data curation, reviewed final version of the manuscript. RS: Conceptualization, methodology, investigation, data curation, supervision, reviewed final version of the manuscript.

\section{Compliance with ethical standards}

Conflict of interest The authors declare that they have no conflict of interest.

Publisher's note Springer Nature remains neutral with regard to jurisdictional claims in published maps and institutional affiliations.

\section{References}

1. Ohlsson A, Shah PS. Paracetamol (acetaminophen) for patent ductus arteriosus in preterm or low birth weight infants. Cochrane Database Syst Rev. 2020;1:Cd010061.

2. Zecca E, Romagnoli C, De Carolis MP, Costa S, Marra R, De Luca D. Does Ibuprofen increase neonatal hyperbilirubinemia? Pediatrics. 2009;124:480-4.

3. Erdeve O, Sarici SU, Sari E, Gok F. Oral-ibuprofen-induced acute renal failure in a preterm infant. Pediatr Nephrol. 2008;23:1565-7.

4. Oncel MY, Yurttutan S, Erdeve O, Uras N, Altug N, Oguz SS, et al. Oral paracetamol versus oral ibuprofen in the management of patent ductus arteriosus in preterm infants: a randomized controlled trial. J Pediatr. 2014;164:510-4.

5. Little DC, Pratt TC, Blalock SE, Krauss DR, Cooney DR, Custer MD. Patent ductus arteriosus in micropreemies and full-term infants: the relative merits of surgical ligation versus indomethacin treatment. J Pediatr Surg. 2003;38:492-6.

6. Dang D, Wang D, Zhang C, Zhou W, Zhou Q, Wu H. Comparison of oral paracetamol versus ibuprofen in premature infants with patent ductus arteriosus: a randomized controlled trial. PLoS ONE. 2013;8:e77888.

7. Al-Lawama M, Alammori I, Abdelghani T, Badran E. Oral paracetamol versus oral ibuprofen for treatment of patent ductus arteriosus. J Int Med Res. 2018;46:811-8.

8. Dash SK, Kabra NS, Avasthi BS, Sharma SR, Padhi P, Ahmed J. Enteral paracetamol or intravenous indomethacin for closure of patent ductus arteriosus in preterm neonates: a randomized controlled trial. Indian Pediatr. 2015;52:573-8.

9. Bagheri MM, Niknafs P, Sabsevari F, Torabi MH, Bahman Bijari B, Noroozi E, et al. Comparison of oral acetaminophen versus ibuprofen in premature infants with patent ductus arteriosus. Iran J Pediatr. 2016;26:e3975.

10. Yang B, Gao X, Ren Y, Wang Y, Zhang Q. Oral paracetamol vs. oral ibuprofen in the treatment of symptomatic patent ductus arteriosus in premature infants: a randomized controlled trial. Exp Ther Med. 2016;12:2531-6.

11. El-Mashad AE, El-Mahdy H, El Amrousy D, Elgendy M. Comparative study of the efficacy and safety of paracetamol, ibuprofen, and indomethacin in closure of patent ductus arteriosus in preterm neonates. Eur J Pediatr. 2017;176:233-40.

12. Kumar A, Gosavi RS, Sundaram V, Oleti TP, Krishnan A, Kiran $\mathrm{S}$, et al. Oral paracetamol vs oral ibuprofen in patent ductus arteriosus: a randomized, controlled, noninferiority trial. J Pediatr. 2020;222:79-84.

13. Meena V, Meena DS, Rathore PS, Chaudhary S, Soni JP. Comparison of the efficacy and safety of indomethacin, ibuprofen, and paracetamol in the closure of patent ductus arteriosus in preterm neonates - a randomized controlled trial. Ann Pediatr Cardiol. 2020;13:130-5.

14. El-Farrash RA, El Shimy MS, El-Sakka AS, Ahmed MG, AbdelMoez DG. Efficacy and safety of oral paracetamol versus oral ibuprofen for closure of patent ductus arteriosus in preterm infants: a randomized controlled trial. J Matern Fetal Neonatal Med. 2019;32:3647-54.

15. Vaidya R, Wilson D, Paris Y, Madore L, Singh R. Use of acetaminophen for patent ductus arteriosus treatment: a single center experience. J Matern Fetal Neonatal Med. 2019;33:1-7.

16. Chorne N, Jegatheesan P, Lin E, Shi R, Clyman RI. Risk factors for persistent ductus arteriosus patency during indomethacin treatment. J Pediatr. 2007;151:629-34.

17. Quinn D, Cooper B, Clyman RI. Factors associated with permanent closure of the ductus arteriosus: a role for prolonged indomethacin therapy. Pediatrics. 2002;110:e10.

18. Yang CZ, Lee J. Factors affecting successful closure of hemodynamically significant patent ductus arteriosus with indomethacin in extremely low birth weight infants. World J Pediatr. 2008;4:91-6.

19. Kim ES, Kim EK, Choi CW, Kim HS, Kim BI, Choi JH, et al. Intrauterine inflammation as a risk factor for persistent ductus arteriosus patency after cyclooxygenase inhibition in extremely low birth weight infants. J Pediatr. 2010;157:745-50.

20. Fenton TR, Kim JH. A systematic review and meta-analysis to revise the Fenton growth chart for preterm infants. BMC Pediatr. 2013;13:59.

21. Evans N. Preterm patent ductus arteriosus: a continuing conundrum for the neonatologist? Semin Fetal Neonatal Med. 2015;20:272-7.

22. Sinha B. Controversies in management of patent ductus arterious in the preterm infant. Pulmon Respir Med. 2013;13:007.

23. Hammerman C, Bin-Nun A, Markovitch E, Schimmel MS, Kaplan M, Fink D. Ductal closure with paracetamol: a surprising new approach to patent ductus arteriosus treatment. Pediatrics. 2011;128:e1618-21.

24. Shepherd JL, Noori S. What is a hemodynamically significant PDA in preterm infants? Congenit Heart Dis. 2019;14:21-6.

25. Alba AC, Agoritsas T, Walsh M, Hanna S, Iorio A, Devereaux PJ, et al. Discrimination and calibration of clinical prediction models: users' guides to the medical literature. Jama. 2017;318:1377-84.

26. Hosmer, DW, Lemeshow S. Assessing the fit of the model. In: Hosmer D, Lemeshow S, editors. Applied logistic regression. 2nd ed. New York: NY: Wiley; 2000. p. 143-202.

27. El-Khuffash A, Jain A, Corcoran D, Shah PS, Hooper CW, Brown $\mathrm{N}$, et al. Efficacy of paracetamol on patent ductus arteriosus closure may be dose dependent: evidence from human and murine studies. Pediatr Res. 2014;76:238-44.

28. Oncel MY, Yurttutan S, Degirmencioglu H, Uras N, Altug N, Erdeve $\mathrm{O}$, et al. Intravenous paracetamol treatment in the management of patent ductus arteriosus in extremely low birth weight infants. Neonatology. 2013;103:166-9.

29. Ahamed MF, Verma P, Lee S, Vega M, Wang D, Kim M, et al. Predictors of successful closure of patent ductus arteriosus with indomethacin. J Perinatol. 2015;35:729-34.

30. Tschuppert S, Doell C, Arlettaz-Mieth R, Baenziger O, Rousson $\mathrm{V}$, Balmer $\mathrm{C}$, et al. The effect of ductal diameter on surgical and 
medical closure of patent ductus arteriosus in preterm neonates: size matters. J Thorac Cardiovasc Surg. 2008;135:78-82.

31. Boo NY, Mohd-Amin I, Bilkis AA, Yong-Junina F. Predictors of failed closure of patent ductus arteriosus with indomethacin. Singap Med J. 2006;47:763-8.

32. Koch J, Hensley G, Roy L, Brown S, Ramaciotti C, Rosenfeld CR. Prevalence of spontaneous closure of the ductus arteriosus in neonates at a birth weight of 1000 grams or less. Pediatrics. 2006;117:1113-21.

33. Nemerofsky SL, Parravicini E, Bateman D, Kleinman C, Polin RA, Lorenz JM. The ductus arteriosus rarely requires treatment in infants $>1000$ grams. Am J Perinatol. 2008;25:661-6.

34. Mitra S, Ronnestad A, Holmstrom H. Management of patent ductus arteriosus in preterm infants-where do we stand? Congenit Heart Dis. 2013;8:500-12.

35. Hills NK, Clyman R. Paracetamol (Acetaminophen) for patent ductus arteriosus: Where do we stand? J Pediatr. 2020;222:18-21.

36. Benitz WE. Hey, doctor, leave the PDA alone. Pediatrics. 2017;140:e20170566.

37. Sankar MN, Bhombal S, Benitz WE. PDA: To treat or not to treat. Congenit Heart Dis. 2019;14:46-51.

38. Liebowitz M, Kaempf J, Erdeve O, Bulbul A, Hakansson S, Lindqvist $\mathbf{J}$, et al. Comparative effectiveness of drugs used to constrict the patent ductus arteriosus: a secondary analysis of the PDATOLERATE trial (NCT01958320). J Perinatol. 2019;39:599-607.
39. Davidson JM, Ferguson J, Ivey E, Philip R, Weems MF, Talati AJ. A randomized trial of intravenous acetaminophen versus indomethacin for treatment of hemodynamically significant PDAs in VLBW infants. J Perinatol. 2020;1-7.

40. Momma K, Hagiwara H, Konishi T. Constriction of fetal ductus arteriosus by non-steroidal anti-inflammatory drugs:study of additional 34 drugs. Prostaglandins. 1984;28:527-36.

41. Clyman RI, Benitz WE. Transcatheter patent ductus arteriosus closure-will history repeat itself? J Perinatol. 2019;39:1435-6.

42. Clyman RI, Ballard PL, Sniderman S, Ballard RA, Roth R, Heymann MA, et al. Prenatal administration of betamethasone for prevention of patient ductus arteriosus. J Pediatr. 1981;98:123-6.

43. Reese J, Shelton EL, Slaughter JC, McNamara PJ. Prophylactic indomethacin revisited. J Pediatr. 2017;186:11-4.e1.

44. Bhombal S, Benitz WE. Prophylactic indomethacin-Is it time to reconsider? J Pediatr. 2017;187:8-10.

45. Viberg H, Eriksson P, Gordh T, Fredriksson A. Paracetamol (acetaminophen) administration during neonatal brain development affects cognitive function and alters its analgesic and anxiolytic response in adult male mice. Toxicol Sci. 2014;138:139-47.

46. Bauer AZ, Kriebel D. Prenatal and perinatal analgesic exposure and autism: an ecological link. Environ Health. 2013;12:41. 